\title{
DOCTRINA
}

\section{El acceso a la información ambiental, la legislación chilena y el Acuerdo de Escazú}

\author{
Access to environmental information, \\ the Chilean legislation and the Escazú Agreement
}

Gonzalo Aguilar (D)

Universidad de Talca, Chile

\begin{abstract}
RESUMEN Este artículo examina los estándares nacionales sobre el acceso a la información ambiental y su compatibilidad con aquellos provenientes del Acuerdo de Escazú. Nuestra visión entiende que, a pesar de los avances realizados en el orden jurídico nacional, estos estándares deben ser actualizados a la luz de los desarrollos recientes reflejados en el Acuerdo de Escazú. El análisis involucra no solamente el orden jurídico positivo, sino también la interpretación que han realizado tanto el Tribunal Constitucional como la Corte Suprema.
\end{abstract}

PALABRAS CLAVE Derechos humanos, derecho al acceso a la información ambiental, Acuerdo de Escazú, Tribunal Constitucional, Corte Suprema.

ABSTRACT This paper aims at examining the national standards on access to environmental information and their compatibility with international standards enshrined in the Escazú Agreement. According with our understanding, even though there has been some progress in the national legal system, the national standards should be updated in the light of the recent developments incorporated into the Escazú Agreement. This analysis considers both the positive legal system and the judicial interpretation coming from the Constitutional Court and the Supreme Court.

KEYWORDS Human Rights, right to access to the environmental information, Escazú Agreement, Constitutional Court, Supreme Court. 


\section{Introducción}

Este trabajo pretende analizar los estándares de protección del derecho al acceso a la información ambiental en el orden jurídico chileno y contrastarlos con aquellos provenientes del Acuerdo de Escazú. En este sentido, la pregunta general que orientará nuestra labor será: ¿Los estándares sobre acceso a la información ambiental reconocidos en el orden jurídico chileno, en legislación y jurisprudencia, son suficientes y concordantes con los que establece el Acuerdo de Escazú?

Nuestra visión inicial es que, si bien se ha avanzado en la consagración del derecho al acceso a la información ambiental en el orden jurídico chileno, aún falta por completar y poner dichos estándares al nivel de los desarrollos más recientes en el ámbito internacional, como es el caso del Acuerdo de Escazú.

El método utilizado a lo largo de este estudio será el de la dogmática jurídica, sin perjuicio de complementarlo con el método de casos en aquellas partes de la investigación en que se analiza jurisprudencia. Este trabajo se encuentra dividido en dos grandes partes. En la primera parte aborda los estándares sobre el acceso a la información ambiental que se encuentran establecidos en el ordenamiento jurídico chileno. En la segunda parte, se examinan algunos ejemplos de desarrollo jurisprudencial de esos estándares.

\section{El derecho al acceso a la información ambiental en el orden jurídico chileno}

El acceso a la información es un derecho fundamental, que en el ordenamiento jurídico chileno tiene el carácter de implícito ya que se desprende del artículo 19 núm. 12 (consagra la libertad de opinión e información) y del artículo 8 (consagra los principios de transparencia, publicidad y probidad) de la Constitución y también de los tratados internacionales concernientes a los derechos humanos (Sanz Salguero, 2017: 145). Entre estos, cabe mencionar el Pacto Internacional de Derechos Civiles y Políticos y la Convención Americana sobre Derechos Humanos (Astudillo Muñoz, 2019: 162-166; Droguett González, 2019: 143). Este derecho implícito se incorpora al ordenamiento jurídico mediante el bloque constitucional de derechos en base al artículo 5, inciso segundo, de la carta fundamental, que posibilita la inclusión de derechos no contemplados de forma expresa en nuestra Constitución (Nogueira Alcalá, 2015: 312 y 313).

En torno al derecho de acceso a la información es necesario mencionar que existe una discusión doctrinaria sobre el hecho de que no existe una consagración expresa del mismo en el texto constitucional vigente, por ello hay diversas posturas en torno a esto. Una de estas posturas tiene que ver con el carácter implícito de este derecho (García y Contreras, 2009: 141 y 142; Vial, 2007: 115). Este carácter de implícito tendría su sustento en el artículo 8 que permitiría afirmar que el acceso a la informa- 
ción es una garantía constitucional (CPLT, 2020: 22; Camacho Cepeda, 2018: 81 y 82). Cabe agregar que el Tribunal Constitucional así lo ha entendido, ya que en base a los artículos 4, 5 inciso segundo, 8 y el artículo 19 núm. 2 se construye este derecho de acceso a la información pública entendido como un deber correlativo al deber de publicidad (Viera-Gallo Quesney, 2013: 181-183).

Con respecto a la publicidad de la información pública, consagrada en el artículo 8 inciso segundo como principio constitucional, cabe señalar que este conlleva que los actos y resoluciones del Estado, así como sus fundamentos y procedimientos son públicos, por lo que la publicidad constituye un principio rector (Fernández González, 2009: 50). El acceso a la información tiene su antecedente en el principio publicidad y el desarrollo del acceso a la información lo ha resuelto el legislador a través del principio constitucional del artículo 8 (Camacho Cepeda, 2013: 33-34; Fernández González, 2014: 61; Tello, Cerna y Pavón, 2009: 195-196), por lo que el acceso a la información está supeditado a la libertad de recibir información pública (Isensee Rimassa y Muñoz Severino, 2013: 48).

En el ámbito internacional, el 4 de marzo de 2018 se firmó el Acuerdo de Escazú, en Costa Rica. Este instrumento jurídico vinculante es el resultado de un esfuerzo mancomunado de los países de América Latina y el Caribe, liderados por Costa Rica y Chile. El objetivo fue negociar un instrumento que tendiera a dar efectividad al Principio 10 de la Declaración de Río de Janeiro. El nombre completo de este tratado es Acuerdo Regional sobre el Acceso a la Información, la Participación Pública y el Acceso a la Justicia en Asuntos Ambientales en América Latina y el Caribe. Luego de la ratificación de Argentina y México el 22 de enero de 2021, el tratado reunió el número de ratificaciones necesarias y entró en vigor el 22 de abril de 2021. Si bien Chile no es parte de este instrumento internacional, sus estándares sirven de guía y orientación para valorar la adecuación de la normativa interna a los estándares internacionales más recientes en materia de derecho al acceso a la información ambiental.

La información ambiental tiene cierta complejidad por efecto de su contenido y de los mecanismos que deben establecerse para su adecuado ejercicio y justiciabilidad. No solo supone solicitar y recibir información sobre materias medioambientales, sus elementos y recursos naturales, sino que también conlleva conocer y comprender los impactos negativos sobre el medio ambiente o la salud de las personas y los instrumentos de gestión ambiental (artículo 2 letra c del Acuerdo de Escazú). El acceso a la información ambiental tiene una indiscutible importancia en una sociedad democrática de derechos. Con motivo del proceso constituyente chileno podría concretarse expresamente este derecho.

En materia de legislación ambiental, cabe mencionar la Ley 19.300 sobre Bases Generales del Medio Ambiente. ${ }^{1}$ Esta ley constituye el marco normativo general en

1. Esta ley fue publicada en el Diario Oficial el 9 de marzo de 1994. Su última modificación fue el 21 de 
materia ambiental, ya que establece la institucionalidad y fija instrumentos de gestión en este ámbito y desarrolla la garantía constitucional de vivir en un medio ambiente libre de contaminación (artículo 19 núm. 8). También existen leyes que mencionan el acceso a la información ambiental, así como algunos reglamentos que aluden o desarrollan este derecho.

\section{Regulación legal y reglamentaria del acceso a la información ambiental}

En materia de legislación ambiental, hay que mencionar la Ley 19.300 sobre Bases Generales del Medio Ambiente. ${ }^{2}$ Esta ley constituye el marco normativo general en materia ambiental, ya que establece la institucionalidad y fija instrumentos de gestión en este ámbito y desarrolla el derecho a vivir en un medio ambiente libre de contaminación.

En lo referente al acceso a la información ambiental, esta ley establece en su artículo 4, inciso primero, el deber del Estado de permitir el acceso a la información ambiental (Cordero y Durán, 2017: 9). ${ }^{3}$ Además, el párrafo $3 .{ }^{\circ}$ bis incorpora el derecho al acceso a la información ambiental, en sus artículos 31 bis al 31 quáter. ${ }^{4}$ En el artículo 31 bis la ley reconoce el derecho de toda persona de acceder a la información de carácter ambiental que esté en poder de la Administración, en conformidad con la Constitución y con la Ley 20.285. Por su parte, el artículo 31 quáter señala que cualquier persona que se considere lesionada en su derecho a acceder a la información ambiental podrá recurrir ante la autoridad competente, de conformidad con lo señalado en la Ley 20.285 (Bertazzo, 2019: 13). Así, el artículo 7 de la Ley 20.285 establece la obligación de mantener actualizada - con una regularidad mensual, al menos- la información en los sitios web de los organismos públicos y que esta se encuentre en forma permanente a disposición de los ciudadanos.

En cuanto al alcance de la noción de información ambiental, el artículo 31 bis de la Ley 19.300 define el concepto como aquella: «de carácter escrita, visual, sonora, electrónica o registrada de cualquier otra forma que se encuentre en poder de la Administración». Asimismo, este precepto enumera una serie de materias que forman parte integrante del concepto de información ambiental. Cabe señalar que esta norma debería interpretarse extensivamente y a la luz de la noción de máxima eficacia

enero de 2020 mediante la Ley 21.202 que modificó diversos cuerpos legales con el objetivo de proteger los humedales urbanos.

2. Esta ley fue publicada en el Diario Oficial el 9 de marzo de 1994.

3. Ley 19.300, artículo 4, inciso primero: «Es deber del Estado facilitar la participación ciudadana, permitir el acceso a la información ambiental y promover campañas educativas destinadas a la protección del medio ambiente».

4. El derecho de acceso a la información ambiental fue incorporado a la Ley 19.30o en virtud de la modificación realizada por la Ley 20.417 de 2010. 
y según el principio pro natura (Fuentes y Cenicacelaya, 2019: 185; Sedano Lorenzo, 2019: 190 y 191; Olivares Gallardo, 2018: 627, 644 y 645).

De esta norma se desprende que forma parte de la información ambiental todo aquello en que se sustenten los actos administrativos referentes a factores y componentes que tengan incidencia o interacción con el medio ambiente, así como las medidas destinadas a conservarlo (Ramírez Parada, 2011: 392). Este concepto, que a primera vista puede parecer amplio, presenta una diferencia importante con el estándar establecido en el Acuerdo de Escazú, ya que en este caso el concepto de información ambiental no queda reducido a la información que está en poder de la Administración. En efecto, el artículo, letra c) del Acuerdo de Escazú señala:

Por «información ambiental» se entiende cualquier información escrita, visual, sonora, electrónica o registrada en cualquier otro formato, relativa al medio ambiente y sus elementos y a los recursos naturales, incluyendo aquella que esté relacionada con los riesgos ambientales y los posibles impactos adversos asociados que afecten o puedan afectar el medio ambiente y la salud, así como la relacionada con la protección y la gestión ambientales (Costa Cordella y Burdiles Perucci, 2019: 189-211).

En cuanto al acceso a la información, las comisiones de evaluación o el director ejecutivo del Servicio de Evaluación Ambiental tienen la obligación de entregar información en lenguaje sencillo, directo y fácil en las instancias de participación ciudadana ambiental. 5 Sin embargo, este deber se circunscribe a los instrumentos de gestión de Estudio de Impacto Ambiental y, eventualmente, de Declaración de Impacto Ambiental, por lo que no cumple el estándar el Acuerdo de Escazú.

El artículo 31 ter de la Ley 19.300 define la creación de un Sistema Nacional de Información Ambiental, administrado por el Ministerio del Medio Ambiente. ${ }^{6} \mathrm{Su}$ rol principal es poner a disposición del público general información de carácter ambiental, como los textos de tratados, los convenios y acuerdos internacionales, así como las leyes, los reglamentos y demás actos administrativos sobre medio ambiente o relacionados con él, las sentencias definitivas de los Tribunales de Justicia sobre juicios de carácter ambiental y los informes sobre el estado del medio ambiente, entre otros documentos. ${ }^{7}$ Ahora bien, ¿es suficiente para cumplir con esta obligación la sola publicación en el sitio web? En cuanto al Sistema Nacional de Información de Fiscalización Ambiental, de acuerdo con el artículo 31 quáter el Ministerio del Medio Ambiente, como órgano de la Administración del Estado, no solo está obligado a entregar la información ambiental, sino que también está obligado a permitir y

5. Artículo 83 del Decreto 40, publicado el 12 de agosto de 2013, que aprobó el Reglamento del Sistema de Evaluación de Impacto Ambiental.

6. Sistema Nacional de Información Ambiental, disponible en https://sinia.mma.gob.cl/que-es-sinia/.

7. Véase artículo 31 ter de la Ley 19.300. 
promover el conocimiento de los procedimientos, contenidos y decisiones. ${ }^{8}$ Como se ha indicado, cualquier persona que considere vulnerado su derecho al acceso a la información ambiental podrá reclamar ante el CPLT.

La misma Ley 19.300 se remite, en la concreción de este derecho, a la Ley $20.285^{9}$ (Bertazzo, 2019: 13), que en su artículo 7 establece el mandato de mantener de forma actualizada - al menos, una vez al mes - la información en sus sitios web y que esta se encuentre de forma permanente a disposición del público. Esta norma enuncia una serie de elementos que deben ser publicitados. ${ }^{10}$ Ante el incumplimiento de este mandato se puede presentar un reclamo ante el CPLT. En base a los principios de transparencia, máxima divulgación y relevancia, deben considerarse para la concreción del acceso a la información pública ambiental, los criterios de disponibilidad, comprensibilidad y relevancia ${ }^{11}$ (Cordero y Durán, 2017: 10).

Respecto del Sistema Nacional de Información de Fiscalización Ambiental (SNIFA), se encuentra disponible la siguiente información ambiental de acceso público:

- Normativa ambiental, como tratados internacionales, acuerdos internacionales, leyes y reglamentos en materia ambiental, resoluciones de calificación ambiental, planes de descontaminación y/o prevención ambiental, normas de calidad y emisión.

- Dictámenes de la Contraloría General de la República en materia ambientales.

- Sentencias definitivas de los tribunales ambientales y de la justicia ordinaria (acciones de protección, casación en la forma y fondo).

- Programas de cumplimiento de reparación ambiental por infractores de la normativa ambiental.

- Registro de sanciones y medidas provisionales en procedimientos sancionatorios.

Algunos problemas que dificultan el acceso a la información tienen relación con los criterios de búsqueda, el idioma utilizado es solo el español y elementos más técnicos de la información disponible dificultan su adecuada comprensión, por lo que el acceso a la información no es inclusiva.

A su vez, el artículo 31 ter de la Ley 19.300 hace referencia a la información que debe estar disponible en el Sistema Nacional de Información Ambiental. Al contrastar esta norma con el artículo 6 párrafo 3 del Acuerdo de Escazú, hay documentos

8. Ver artículo 1,2 y 3 de la Ley 20.285 , de 2008.

9. Artículo 31 quáter de la Ley 19.300.

10. La información que deben contener los sititos electrónicos de los órganos del Estado se especifica en el artículo 7 de la Ley 20.285 .

11. Los principios esenciales que rigen el acceso a la información se encuentran especificados en el artículo 11 de la Ley 20.285 . 
o tipo de información que deberían ser parte del sistema chileno, como estudios de carácter académico sobre materias ambientales, el listado de zonas contaminadas y latentes por contaminante y fuentes relativas al cambio climático.

Un ejemplo del tipo de documento que el sistema debiera recoger es el Informe Nacional sobre el Estado del Medio Ambiente publicado por el Ministerio del Medio Ambiente, en que se tratan diversos temas que tienen que ver con la sustentabilidad, los océanos, la biodiversidad, los pueblos indígenas, entre otros, cuya finalidad es ser una herramienta de información. El último informe es del 2020.

Por otra parte, faltaría incorporar en la normativa los incentivos adecuados para que las empresas, tanto públicas como privadas, elaboren informes periódicos de sostenibilidad, que sean accesibles al público, en distintos formatos, comprensibles y en lenguaje sencillo, que incorporen pormenorizadamente la variante económica, social, ambiental y de derechos humanos, considerando la perspectiva de los grupos o pueblos especialmente vulnerables.

Estas disposiciones mostrarían que no se alcanza a satisfacer el estándar del Acuerdo de Escazú. En efecto, tal como se señala en dicho instrumento, en relación con el Informe Nacional sobre el Estado del Medio Ambiente a que se refiere el artículo 6 párrafo 7, el Estado debe garantizar que este informe sea accesible a todo el público, incluyendo a las personas y grupos en situación de vulnerabilidad, considerando sus idiomas y medios de difusión culturalmente apropiados, e incluso, considerando la posibilidad de su participación en su confección. Ninguna de las normas antes mencionadas sobre acceso a la información ambiental son suficientes para alcanzar este estándar.

Si bien, esta es la norma general, también existen algunas leyes y reglamentos que tratan sobre el acceso a la información ambiental. Por un lado, existe la Ley 20.283 sobre recuperación del bosque nativo y fomento forestal. ${ }^{12}$ En su artículo 4 , inciso segundo, señala al deber de crear un catastro forestal que «deberá ser actualizado a lo menos cada diez años y su información tendrá carácter público». Por otro lado, la Ley $\mathbf{2 1 . 2 0 2}$ que protege los humedales urbanos establece el carácter público del expediente de solicitud de reconocimiento del humedal, lo cual es regulado en su reglamento.

La Ley 21.151 en su artículo 5 señala:

Los afrodescendientes chilenos a que hace referencia el artículo 2 de esta ley tienen el derecho a ser consultados mediante el Convenio 169, de la Organización Internacional del Trabajo, sobre Pueblos Indígenas y Tribales en Países Independientes,

12. El objeto de esta ley es proteger, recuperar y mejorar las especies nativas del país, asegurando su sustentabilidad forestal, mediante planes de manejo y preservación del bosque nativo. Publicada en el Diario Oficial el 30 de julio de 2008. 
cada vez que se prevea dictar medidas legislativas o administrativas susceptibles de afectarles directamente. ${ }^{13}$

Esta norma es relevante en la medida en que, en materia ambiental, debe existir participación de los afrodescendientes en el procedimiento de evaluación ambiental.

Por otra parte, desde el punto de vista reglamentario, el artículo 10, letras f) y g) del Reglamento Orgánico del Ministerio del Medio Ambiente le asigna a la División de Información y Economía Ambiental la responsabilidad de administrar el Sistema Nacional de Información Ambiental y de implementar y administrar un sistema de información pública sobre el cumplimiento y aplicación de la normativa ambiental de carácter general vigente, incluyendo un catastro completo y actualizado de dicha normativa, el que debe ser de libre acceso y disponible por medios electrónicos. ${ }^{14}$

Asimismo, el Reglamento para la Evaluación Ambiental Estratégica establece, en su artículo 8, el Sistema de Información de Evaluación Ambiental Estratégica, que debe ser de acceso al público y que contendrá, en general, información electrónica «destinada a la consulta y seguimiento del procedimiento de Evaluación Ambiental Estratégica de las políticas, planes e instrumentos de ordenamiento territorial».15

Por su parte, el inciso final del Reglamento del Sistema de Evaluación de Impacto Ambiental (RSEIA) consagra el principio de que el expediente es público y debe encontrarse a disposición del público para su consulta. El artículo 22 del RSEIA reviste una importancia fundamental ya que consagra la figura de la reserva de información a solicitud del interesado. Dicho artículo reza como sigue:

El expediente de evaluación ambiental será público, a excepción de los documentos o piezas que contengan los antecedentes técnicos, financieros y otros que, a petición del interesado, se estimare necesario substraer del conocimiento público, para asegurar la confidencialidad comercial e industrial o proteger las invenciones o procedimientos patentables del proyecto o actividad a que se refiere el Estudio o Declaración de Impacto Ambiental.

La misma norma en su inciso final consagra una excepción a la reserva:

En ningún caso se podrá mantener en reserva la información relacionada con los efectos, características o circunstancias establecidos en el artículo 11 de la Ley y, en el caso de las Declaraciones, aquella información que se relaciona con las cargas ambientales. ${ }^{16}$

13. La Ley 21.151 otorga reconocimiento legal al pueblo tribal afrodescendiente chileno. Publicada en el Diario Oficial 16 de abril de 2019.

14. Ministerio del Medio Ambiente, Decreto 62, publicado el 12 de marzo de 2015.

15. Ministerio del Medio Ambiente, Decreto 32, publicado el 4 de noviembre de 2015.

16. El artículo 11 se refiere a las normas de calidad ambiental y emisión. 
Las normas anteriores no permiten responder a la pregunta de qué ocurre cuando el titular del proyecto omite información, la que, finalmente, puede resultar relevante para el caso. Cabe recordar que la Corte Suprema, en el denominado caso Gaviotín Chico, acogió un recurso de protección en el que los recurrentes denunciaban que el titular del proyecto, una empresa que pretendía construir una bodega de transferencia de concentrado de cobre en Mejillones, omitió en su declaración ante el servicio toda consideración de la existencia en el área de una zona de nidificación o influencia de la especie gaviotín chico, y no se reparó en ello. Incluso el ministro Muñoz estuvo por mantener la orden de paralización de la obra, dispuesta por la Corte de Apelaciones, «teniendo en especial consideración para ello el incumplimiento, por parte del proyectista, de su obligación de informar oportuna y verazmente al Servicio de Evaluación Ambiental el riesgo que hoy se ha detectado y resulta indispensable prevenir». ${ }^{17}$

Del mismo modo, las normas indicadas no aluden a un plazo en el cual se debe generar la respuesta ante la solicitud de información ambiental, y aplica supletoriamente lo establecido en el artículo 14 de la Ley 20.285, que indica que el plazo máximo para la entrega de la información solicitada es de veinte días hábiles desde la recepción de la solicitud. En este punto, por tanto, la normativa tampoco se encuentra al nivel de los estándares de Escazú. En efecto, en el Acuerdo de Escazú se señala que la autoridad competente debe entregar la información ambiental solicitada con la máxima celeridad posible y en un plazo no superior a treinta días hábiles contados a partir de la fecha de recepción de la misma o en un plazo menor si así lo dispone la normativa interna. Si la autoridad competente requiere más tiempo, debe así notificarlo al solicitante, por escrito, expresando la justificación correspondiente, antes del vencimiento del plazo, no pudiendo exceder, el suplemento de tiempo, de diez días hábiles (artículo 5 párrafo 12 y 13).

Finalmente, el artículo 89 del RSEIA establece el derecho de las personas a acceder y conocer «el contenido del Estudio de Impacto Ambiental y el tenor de los documentos acompañados, sin perjuicio de lo expresado en el artículo 22 del presente Reglamento, en cualquier etapa de tramitación del procedimiento». ${ }^{18}$

Estas disposiciones refieren a la facultad de conocer el expediente en cualquier etapa de tramitación del procedimiento, pero no hay una salvaguarda en el sentido de conocer los detalles del proyecto desde las etapas más tempranas de su concepción, diseño y planificación. Y luego, en cuanto a las barreras al acceso a la información ambiental, la norma contempla la facultad de acceder a las copias del expediente, pero a costas del solicitante. Aparentemente, la norma no contempló excepciones a los costos de acceso en caso de grupos vulnerables, para quienes, muchas veces, estas

17. Corte Suprema, rol 21.432-2019, sentencia de fecha 24 de octubre de 2019, prevención.

18. Ministerio del Medio Ambiente, Decreto 40, publicado el 12 de agosto de 2013. 
barreras pueden ser insuperables. En consecuencia, en este punto se apreciar una diferencia con el estándar de Escazú. En efecto, según dicho instrumento la autoridad debe entregar la información ambiental solicitada sin costo, salvo en caso de reproducción o envío de antecedentes (artículo 5 párrafo 17). Aquí ya se percibe un cambio de enfoque en relación con el mismo criterio en el Convenio de Aarhus. El Acuerdo de Escazú señala que los costos deben ser razonables, deben ser informados anticipadamente, y se podrá liberar al solicitante en caso de personas o grupos vulnerables o causa justificada (artículo 5 párrafo 17).

También existe el Reglamento para la Dictación de Normas de Calidad Ambiental y de Emisión. ${ }^{19}$ Este reglamento establece que la tramitación del proceso de dictación de normas de calidad y emisión dará origen a un expediente público, escrito o electrónico. ${ }^{20}$ Dicho expediente «contendrá las resoluciones que se dicten, las consultas evacuadas, las observaciones que se formulen, así como todos los antecedentes, datos y documentos relativos a la dictación de la norma» (artículo 8, inciso primero).

Además, el Reglamento que regula el Procedimiento de Consulta Indígena establece la realización de la consulta ante medidas administrativas o legislativas susceptibles de afectarles directamente. ${ }^{21}$ Se entiende que estas medidas causan impacto significativo cuando afectan «el ejercicio de sus tradiciones y costumbres ancestrales, prácticas religiosas, culturales o espirituales, o la relación con sus tierras indígenas» (artículo 7). En el caso de proyectos o actividades que ingresan al Sistema de Evaluación Ambiental se debe llevar a cabo la consulta dentro de este procedimiento. En lo referente al acceso a la información, el Reglamento contempla, en el artículo 16 letra b), la entrega de información con la finalidad de proporcionar «todos los antecedentes de la medida a consultar a los pueblos indígenas, considerando los motivos que la justifican, la naturaleza de la medida, su alcance e implicancias».

Este precepto, si bien afirma el principio de la entrega oportuna de la información, no establece un criterio razonable y proporcionado para la entrega de la información, que permita satisfacer el criterio de predictibilidad para el justiciable. Igualmente, no hay referencias al criterio de las barreras económicas en el acceso a la información cuando los pueblos indígenas están involucrados. En efecto, en el Acuerdo de Escazú las partes suscriptoras acordaron darle un tratamiento especial a las personas y los grupos en situación de vulnerabilidad, atendiendo su caso particular (artículo 5 párrafo 3 y 4). Este diseño coincide con el principio del derecho de los derechos humanos relativo al deber del Estado de proporcionar una protección reforzada para este tipo de grupos (Beltrao y otros, 2014: 314). Además, el Acuerdo de Escazú señala

19. Ministerio del Medio Ambiente, Decreto 38, publicado el 22 de julio de 2013.

20. Véase el artículo 9 del Reglamento para la Dictación de Normas de Calidad Ambiental y de Emisión.

21. Ministerio de Desarrollo Social, Decreto Promulgatorio 66, publicado el o4 de marzo de 2014. 
que el Estado debe garantizar el acceso a la información ambiental a las personas o grupos en situación de vulnerabilidad. El artículo 2 letra e) define este concepto:

Por personas o grupos en situación de vulnerabilidad se entiende aquellas personas o grupos que encuentran especiales dificultades para ejercer con plenitud los derechos de acceso reconocidos en el presente Acuerdo, por las circunstancias o condiciones que se entiendan en el contexto nacional de cada Parte y de conformidad con sus obligaciones internacionales.

Además, el Estado debe asegurar la divulgación de la información ambiental en varios idiomas según se usen en el país, y utilizar los formatos y los canales y vías de comunicación que sean culturalmente adecuados (artículo 6 párrafo 6).

Por su parte, el Reglamento de la Ley 20.283 sobre Recuperación del Bosque Nativo y Fomento Forestal establece, en su artículo 29, que la Corporación Nacional Forestal mantendrá en su sitio web un registro público de planes de manejo aprobados. ${ }^{22}$

Asimismo, el Reglamento de la Ley $\mathbf{2 1 . 2 0 2}$ que protege los Humedales Urbanos, establece dentro de su normativa, específicamente en la solicitud realizada a un municipio relativa al reconocimiento de un humedal, el carácter público del expediente que contenga la solicitud y los documentos y actuaciones relacionadas. ${ }^{23}$

Como se aprecia, de las normas jurídicas señaladas, la legislación tanto general como sectorial, consagra, como regla general, el acceso a la información ambiental, estableciendo algunas excepciones de reserva de información que pretende cautelar los derechos del interesado, cuya consecuencia es sustraer información «sensible» del conocimiento público. Desde el punto de vista de los estándares internacionales, estas restricciones al acceso a la información no se condicen con el principio de máxima divulgación y tampoco considera las especiales características de la información ambiental (Cepal, 2018: 67-69). ${ }^{24}$

\section{Control administrativo y acceso a la información ambiental}

La normativa de acceso a la información no distingue entre información ambiental y el resto de información (Bermúdez Soto, 2010: 572). Por esta razón, el control del cumplimiento de la normativa sobre acceso a la información ambiental le corresponde al CPLT.

El artículo 31 quáter de la Ley 19.300 señala que toda persona que se vea lesionada en su derecho al acceso a la información ambiental dispondrá de la reclamación ante

22. Ministerio de Agricultura, Decreto Promulgatorio 93, de 2009. Corchetes nuestros.

23. Véase el artículo 7, del Ministerio del Medio Ambiente y Ministerio de Obras Públicas, Decreto Promulgatorio 15, publicado el 24 de noviembre de 2020.

24. Véase la Declaración de Río sobre Medio Ambiente y Desarrollo, 1992, Principio 10. 
el CPLT, según lo establecido en la Ley 20.285. Este órgano puede acoger la reclamación y permitir el acceso a la información ambiental denegada otorgándole un plazo prudencial a la Administración para entregar la información requerida, o bien, puede denegar el acceso a la información. En este último caso la persona afectada puede reclamar de la ilegalidad de esta resolución ante la Corte de Apelaciones respectiva.

En la tabla 1 se pueden observar los reclamos deducidos ante el CPLT desde la entrada en vigor de la Ley 20.417, esto es, el 26 de enero del año 2010. Como se ve, el total de reclamos deducidos ante el CPLT por vulneración del acceso a la información ambiental es de 225. En el análisis que se realiza a continuación solo se considera los reclamos rechazados y acogidos, que son 147. El resto de los reclamos, que no serán objeto de nuestro análisis, son 78 . Estos últimos, se dividen entre inadmisibles (49), se considera entregada la información (19) y reclamos desistidos (10).

De los datos de la tabla 1 se observa que 45 reclamos de un total de 225 fueron rechazados. Esto corresponde al $20 \%$ del total. Dentro de las razones aducidas por el CPLT para rechazar estos reclamos están las siguientes: ${ }^{25}$

- La información entregada al peticionario es la única existente en poder del órgano reclamado, por lo que se entiende cumplido el deber de entrega de información (1).

- Ser presentado de forma extemporánea (1).

- El órgano de la Administración requerido no es competente para ocuparse de la solicitud de información o no posee los documentos solicitados. Por ello enviará de inmediato la solicitud a la autoridad que sea competente para conocer de ella, en la medida que esta sea posible de individualizar, informando de ello al peticionario (3).

- Inexistencia material de la información consultada (16).

- Afecta los derechos de las personas, particularmente tratándose de su seguridad, su salud, la esfera de su vida privada o derechos de carácter comercial o económico (9).

- Tratarse de antecedentes o deliberaciones previas a la adopción de una resolución, medida o política, sin perjuicio que los fundamentos de aquéllas sean públicos una vez que sean adoptadas (8).

- Por estar la información solicitada permanentemente a disposición del público (3).

- Se cumplió con la entrega de la información solicitada (3).

- Por aplicación del principio de transparencia de la función pública (1).

25. Entre paréntesis se indica el número de casos en que se invoca la razón. 
Tabla 1. Reclamos deducidos ante el COLT según institución

\begin{tabular}{|c|c|c|c|c|}
\hline Institución & Reclamos & Decisión del Consejo & Período & Total \\
\hline \multirow{5}{*}{ Ministerio del Medio Ambiente } & 11 & Acogido* & $2011-2018$ & \multirow{5}{*}{26} \\
\hline & 3 & Rechazado & $2013-2016$ & \\
\hline & 2 & Desistido & $2014-2015$ & \\
\hline & 6 & Inadmisibles & $2015-2016$ & \\
\hline & 4 & Da por entregada información & $2012-2016$ & \\
\hline \multirow{5}{*}{ Superintendencia del Medio Ambiente } & 13 & Acogido & $2013-2020$ & \multirow{5}{*}{47} \\
\hline & 16 & Rechazo & $2014-2020$ & \\
\hline & 2 & Desistido & $2013-2020$ & \\
\hline & 12 & Inadmisible & $2014-2020$ & \\
\hline & 4 & Da por entregada información & $2016-2020$ & \\
\hline \multirow{5}{*}{ Servicio de Evaluación Ambiental } & 17 & Acogido & $2012-2019$ & \multirow{5}{*}{69} \\
\hline & 10 & Rechazado & $2012-2020$ & \\
\hline & 5 & Desistido & $2012-2019$ & \\
\hline & 29 & Inadmisible & $2011-2019$ & \\
\hline & 8 & Da por entregada información & $2016-2020$ & \\
\hline \multirow{4}{*}{ Servicio Agrícola y Ganadero } & 16 & Acogido & $2010-2020$ & \multirow{4}{*}{22} \\
\hline & 4 & Rechazado & $2018-2020$ & \\
\hline & 1 & Inadmisible & 2012 & \\
\hline & 1 & Da por entregada información & 2020 & \\
\hline \multirow{4}{*}{ Corporación Nacional Forestal } & 22 & Acogido & $2010-2020$ & \multirow{4}{*}{26} \\
\hline & 3 & Rechazado & $2010-2018$ & \\
\hline & 0 & Inadmisible & - & \\
\hline & 1 & Da por entregada información & 2020 & \\
\hline \multirow{4}{*}{ Servicio Nacional de Pesca } & 17 & Acogido & $2010-2020$ & \multirow{4}{*}{23} \\
\hline & 6 & Rechazado & $2017-2020$ & \\
\hline & 0 & Inadmisible & - & \\
\hline & 0 & Da por entregada información & - & \\
\hline \multirow{5}{*}{ Dirección General de Agua } & 6 & Acogido & $2010-2017$ & \multirow{5}{*}{12} \\
\hline & 3 & Rechazado & $2011-2017$ & \\
\hline & 1 & Inadmisible & 2013 & \\
\hline & 1 & Desistido & 2016 & \\
\hline & 1 & Da por entregada información & 2020 & \\
\hline \multicolumn{4}{|l|}{ Total de reclamos } & 225 \\
\hline
\end{tabular}

* Dentro de esta categoría se consideran los total y parcialmente acogidos.

Elaboración propia. Fuente: Consejo para la Transparencia (https://jurisprudencia.cplt.cl/cplt/) . 
Asimismo, se observa que 102 reclamos fueron acogidos. Esto corresponde al $45,3 \%$ del total. Dentro de las razones esgrimidas por el CPLT para acoger los reclamos están las siguientes:

- No se configura causal de reserva de información (artículo 21 núm. 2), ya que el carácter público de la información ambiental y su divulgación no afectan derechos económicos y/o comerciales (34). ${ }^{26}$

- No se configura la causal de reserva del artículo 21 núm. 1 letra b) cuando su publicidad, comunicación o conocimiento afecte el debido cumplimiento de las funciones del órgano requerido, ${ }^{27}$ sosteniendo el régimen general de publicidad ambiental y el principio de publicidad y transparencia del artículo 8 de la Constitución (12).

- Se incumplió el artículo 13 de la Ley de Transparencia ya que no se procedió a derivar la solicitud de acceso a la información al órgano correspondiente (7).

- La información requerida es pública conforme lo establece la Ley de Transparencia y obra en poder del órgano reclamado (7).

- Se acogió el reclamo y se tuvo por cumplida la obligación del órgano reclamado de otorgar la información requerida, aunque en forma extemporánea (10).

- El órgano acoge el reclamo fundando en el artículo 1o de la Ley de Transparencia que consagra el derecho de acceso a la información pública (12).

- Se desestima la inexistencia de los antecedentes requeridos, y se trata de información que por su propia naturaleza y funciones legales, se encuentra dentro de la esfera u órbita de control y a disposición permanente del órgano requerido (1).

- No se configura causal de reserva de información del artículo 21 núm. 1 letra c), ya que no se refiere a un elevado número de actos administrativos o sus antecedentes o cuya atención requiera distraer indebidamente a los funcionarios del cumplimiento regular de sus labores habituales (4).

- No se configura causal de reserva de información del artículo 21 núm. 4, ya que

26. Consejo para la Transparencia, rol C3106-17, Ximena Jirón Verdaguer con Ministerio del Medio Ambiente, considerandos sexto a noveno.

27. «Que, este Consejo ha sostenido reiteradamente que, para configurar dicha hipótesis de secreto o reserva, se requiere la concurrencia de dos requisitos copulativos, a saber: a) que la información requerida sea un antecedente o deliberación previa a la adopción de una resolución, medida o política; y b) que su conocimiento afecte el debido cumplimiento de las funciones del órgano», CPLT, rol C3625-16, considerando quinto. 
se estima que no hay afectación al interés nacional, en especial si se refieren a la salud pública o las relaciones internacionales y los intereses económicos o comerciales del país (1).

- El CPLT acoge el reclamo basado en que la Administración incumplió con su obligación de informar, al no comunicar al solicitante la fuente, el lugar y la forma en que puede tener acceso a dicha información, según lo señalado en el artículo 15 Ley de Transparencia (3).

- Cuando la información solicitada no obra en poder del órgano requerido o ella es inexistente, este debe informar tal circunstancia al requirente (1).

- No se configura causal de reserva de información del artículo 21 de la Ley de Transparencia (7).

- Se acogió el reclamo basándose en el derecho de acceso a la información medioambiental estipulado en el artículo 31 bis Ley 19.300 (3).

Uno de los argumentos más recurrentes para impedir el acceso a la información ambiental es que ello afectaría «derechos económicos y/o comerciales» del titular requerido. En este sentido, el CPLT ha establecido los criterios orientadores que podrían permitir delimitar este concepto:

Se hace presente que este Consejo ha adoptado los siguientes criterios orientadores para determinar si la entrega de la información puede afectar los derechos económicos y comerciales de una persona, natural o jurídica: a) ser secreta, es decir, no generalmente conocida ni fácilmente accesible para personas introducidas en los círculos en que normalmente se utiliza ese tipo de información; b) ser objeto de razonables esfuerzos para mantener su secreto; $y c$ ) tener un valor comercial por ser secreta, esto es, que dicho carácter proporcione a su titular una ventaja competitiva (y por el contrario, su publicidad afecte significativamente su desenvolvimiento competitivo) (CPLT, rol C3106-17, considerandos sexto a noveno).

En la tabla 2 se detalla el mandato del CPLT al órgano de la Administración que ha incumplido con su deber de garantizar el acceso a la información ambiental. Los datos entregados fueron construidos a partir de los 102 reclamos acogidos. Como se puede apreciar, en un $57 \%$ de los casos se decreta la entrega de la información en un plazo de cinco días hábiles. Asimismo, se observa que el CPLT, si bien ordena la entrega de la información requerida, no formula un reproche a la autoridad por el incumplimiento de su obligación.

A partir de lo observado en las tablas, se pueden extraer las siguientes apreciaciones:

a) La información ambiental solicitada es bastante diversa y transversal a toda la institucionalidad ambiental. Las personas que solicitan información a los órganos, pertenecientes a dicha institucionalidad, encuentran una serie de obstáculos de iure 
Tabla 2. Mandatos del CPLT al órgano de la Administración para el acceso a la información ambiental

\begin{tabular}{|c|c|}
\hline Orden & Casos \\
\hline Se requirió a la requerida la entrega de la información. & 2 \\
\hline $\begin{array}{l}\text { Se requirió la entrega de la información solicitada dentro de un plazo de cinco días desde que la resolución quede } \\
\text { ejecutoriada y se representó a la autoridad por infracción al artículo } 13 \text { de la Ley de Transparencia por derivar parte } \\
\text { de la solicitud de información formulada, en circunstancia que era competente para responderla. }\end{array}$ & 2 \\
\hline $\begin{array}{l}\text { Se derivó al Servicio de Evaluación Ambiental la solicitud de acceso a la información y se representó a la autoridad } \\
\text { por incumplimiento del artículo } 13 \text { de la Ley de Transparencia. }\end{array}$ & 3 \\
\hline $\begin{array}{l}\text { Se requirió la entrega de la información solicitada dentro de un plazo de cinco hábiles días desde que la resolución } \\
\text { quede ejecutoriada. }\end{array}$ & 58 \\
\hline $\begin{array}{l}\text { Se requirió la entrega de la información solicitada dentro de un plazo de quince días hábiles desde que la resolución } \\
\text { quede ejecutoriada. }\end{array}$ & 12 \\
\hline $\begin{array}{l}\text { Se requirió la entrega de la información solicitada dentro de un plazo de diez días hábiles desde que la resolución } \\
\text { quede ejecutoriada. }\end{array}$ & 14 \\
\hline Se tuvo por entregada extemporáneamente la información solicitada. & 10 \\
\hline $\begin{array}{l}\text { Se requirió la entrega de la información solicitada dentro de un plazo de treinta días hábiles desde que la resolución } \\
\text { quede ejecutoriada. }\end{array}$ & 1 \\
\hline
\end{tabular}

Elaboración propia. Fuente: Consejo para la Transparencia (https://jurisprudencia.cplt.cl/cplt/).

y de facto para concretar su derecho al acceso a la información ambiental. Los obstáculos de iure los encontramos en la propia Ley de Transparencia, que establece la situación excepcional de reserva, que es utilizada para proteger derechos de particulares (comerciales y/o económicos) por sobre el acceso la información ambiental. Los obstáculos de facto son el modo de acceder a la información, a quién solicitarla y el breve plazo de entrega.

b) En la mayoría de los casos en que el CPLT revirtió la decisión del órgano ambiental, accediendo a la entrega de la información, fue por no acreditarse la causal de reserva de artículo 21 de la Ley de Transparencia.

c) Resulta paradojal que el órgano llamado a conocer de los reclamos por denegación de acceso a la información ambiental no sea especializado en materia ambiental. Si se analizan los argumentos por los que se concede el acceso a la información ambiental se puede apreciar que el principal fundamento es la norma general y no la disposición especial relativa al derecho al acceso a la información ambiental.

\section{¿Cuáles son los estándares de acceso a la información ambiental que ha fijado la jurisprudencia chilena?}

En este punto serán analizados algunos casos de jurisprudencia del Tribunal Constitucional y de la Corte Suprema chilenos. Esto nos permite efectuar un análisis crítico sobre la interpretación judicial relativa al derecho al acceso a la información ambiental. 


\section{Jurisprudencia constitucional}

En esta parte analizaremos algunas sentencias del Tribunal Constitucional chileno respecto de requerimientos de inaplicabilidad por inconstitucionalidad en las que el organismo se pronuncia acerca del acceso a la información ambiental. El periodo analizado corresponde a los años 2016 al 2020.

En los casos examinados se impugnan como inconstitucionales las normas legales que consagran el derecho a la información ambiental (artículo 31 bis Ley 19.300) y las normas legales que establecen el carácter público de la información que se encuentra en poder de los órganos del Estado y aquella elaborada con presupuesto público (artículo 5, inciso segundo, Ley 20.285) y, además, la normativa que consagra el derecho al acceso a la información de actos, resoluciones, actas, acuerdos, contratos y expedientes y a toda información elaborada con presupuesto público (artículo 10, inciso segundo, Ley 20.285).

Por otra parte, el sujeto legitimado activo de los requerimientos de inaplicabilidad en estudio son empresas privadas, del rubro de producción de salmones de cultivo, que buscan priorizar sus derechos económicos y/o comerciales por sobre el acceso a la información ambiental, referente a la clase y tipo de antibióticos utilizados en los salmones.

En la fundamentación esgrimida por el Tribunal Constitucional sobresalen algunos elementos: a) el acceso a la información ambiental afectaría derechos comerciales del interesado; b) la información ambiental en manos de la Administración no es pública; c) la información entregada al Estado por empresas o corporaciones privadas no es pública.

\section{El acceso a la información ambiental afectaría derechos} económicos $y / o$ comerciales del interesado

Los jueces constitucionales ponen en tela de juicio que la Constitución reconozca un derecho al acceso a la información ambiental y, en todo caso, lo aborda restrictivamente. Si la información requerida afecta derechos de particulares o «derechos de las personas», los que sí gozan de protección constitucional, los derechos de las personas deben considerarse como excepciones a la publicidad por sobre el acceso a la información ambiental (Tribunal Constitucional, rol 4986-2018-INA, considerando 18..$^{\circ}$ ). En esta lectura, el Tribunal Constitucional no considera los estándares particulares que rigen el acceso a la información ambiental, más exigentes que aquellos que regulan el acceso a la información en general. En el sistema de estándares que rige el acceso a la información ambiental, las restricciones al acceso o la reserva de información es excepcionalísima, tal como da cuenta lo dispuesto en el Acuerdo de Escazú.

En esta materia, en la causa rol 2907-15-INA el conflicto constitucional consiste en determinar si la norma sobre acceso a la información, en especial, aquella ambien- 
tal, excede o no el marco constitucional. Asimismo, el requirente de inaplicabilidad aduce una afectación a sus derechos, específicamente el secreto industrial, que se vería afectado por la entrega de la información desagregada sobre la utilización de antibióticos y/o pesticidas en la producción de salmones. Cabe señalar que el tribunal no entra al análisis del derecho aparentemente conculcado.

Adicionalmente, los jueces constitucionales señalan que la norma constitucional establece, como excepción a la publicidad de la información, la afectación de los derechos de las personas. Esta excepción se encuentra regulada por el legislador al consagrar las causales de reserva, particularmente, tratándose de su seguridad, su salud, la esfera de su vida privada o los derechos de carácter comercial o económico.

\section{La información ambiental en manos de la Administración no es necesariamente pública}

El argumento que aquí se plantea es que no toda información en poder del Estado es pública. Los jueces constitucionales arriban a esta conclusión mediante el uso de una interpretación restrictiva del marco constitucional, entendiendo que el constituyente especificó qué información era pública. Además, el Tribunal interpreta que no fue intención del constituyente consagrar el derecho al acceso a la información.

Un conflicto constitucional de similar naturaleza relacionado con el derecho al acceso a la información ambiental se plantea en los casos 3111-16-INA, 4986-2018INA y 5950-19-INA, donde lo que se discute es si la información que posee la Administración es pública y, por tanto, debe ser accesible al público.

En las causas 2907-15-INA, 3111-16-INA, 4986-2018-INA y 5950 -19- INA, el Tribunal Constitucional entiende que el artículo 8 de la Constitución no abarca la publicidad de toda la información que se encuentre en manos de la Administración. En efecto, basándose en la historia legislativa del artículo 8, el Tribunal comprende que existe una restricción al acceso a la información entregada por privados a los órganos estatales encargados de su fiscalización. ${ }^{28}$ En este sentido, el Tribunal Constitucional realiza una interpretación restrictiva del derecho al acceso a la información ambiental. En efecto, los jueces constitucionales declaran la inaplicabilidad de las normas legales que consagran el derecho al acceso a la información ambiental, entendiendo que excede el ámbito constitucional garantizado por el artículo 8 de la carta fundamental, que consagra el principio de publicidad y el acceso a la información. ${ }^{29}$

28. Tribunal Constitucional, rol 2907-15- INA, considerando $24 . .^{\circ}$; rol 3111-16- INA, considerandos 22. $.^{\circ}, 34 .^{\circ}$ y $36 .^{\circ}$; rol 4986-2018-INA, considerando decimotercero y decimoctavo; rol 5950-19-INA, considerando decimocuarto.

29. Tribunal Constitucional, rol 2907-15-INA, considerandos $25 .^{\circ}, 27 .^{\circ}, 33 .^{\circ}, 35 .^{\circ}$ y $38 .^{\circ} ;$ rol $3111-16$-INA, considerandos $22 .^{\circ}, 29 .^{\circ}, 30 .^{\circ}$ y $40 .^{\circ} ;$ rol $4986-2018$-INA, considerandos $25 .^{\circ}, 26 .^{\circ}, 31 .^{\circ}$ a $35 .^{\circ}$; rol $5950-19-$ INA, considerandos $10^{\circ}, 21 .^{\circ}$ a $25^{\circ}$, y rol $3974-18$-INA, considerando undécimo. 
Además, la interpretación restrictiva consiste también en que el Tribunal Constitucional entiende que no toda la información en poder del Estado es pública. Solo será pública aquella información respecto de actos, resoluciones, procedimientos $\mathrm{y}$ fundamentos de los propios órganos del Estado. ${ }^{30} \mathrm{El}$ tribunal va más allá y señala que la Constitución no consagra el principio de transparencia, no establece de forma expresa el derecho al acceso a la información y no utiliza la expresión información, agregando que el texto actual no consagra una obligación de entregar la información. ${ }^{31}$ Este razonamiento de los jueces constitucionales no está en línea con los estándares establecidos en el Acuerdo de Escazú. En efecto, el Acuerdo de Escazú reitera el principio de interpretación restrictiva de las limitaciones al derecho. Esto quiere decir que las causales de denegación o rechazo son de derecho estricto. En efecto, los motivos de denegación deben ser interpretados conforme al principio de interpretación restrictiva (artículo 5 párrafo 8 ).

Una vez más es posible observar la influencia del derecho internacional de los derechos humanos en el derecho internacional del medio ambiente, en este caso, en relación con los derechos de acceso. ${ }^{32}$ En efecto, el principio de interpretación restrictiva de las limitaciones a estos derechos humanos es una manifestación del principio pro homine (UNEP, 2019: 99). Y, desde el punto de vista procesal, el principio pro homine tiene una consecuencia en relación con la prueba y, especialmente, con la carga de la prueba u onus probandi. En efecto, el Acuerdo de Escazú señala que la carga de la prueba recaerá en la autoridad competente, lo que implica una inversión en el peso de la prueba (artículo 5 párrafo 8 , parte final).

Las razones de la denegación o rechazo de la solicitud y su interpretación deben ser una de las cuestiones más relevantes de todo el derecho al acceso a la información ambiental. En este contexto, el Acuerdo de Escazú proporciona una serie de principios y criterios que permiten guiar la acción de las partes involucradas.

30. Tribunal Constitucional, rol 2907-15- INA, considerando 25. ${ }^{\circ}$; Tribunal Constitucional, rol 311116-INA, considerando 22..$^{\circ}$; Tribunal Constitucional, rol 5950-19-INA, considerando $13 .^{\circ}$.En ello el Tribunal ha indica que «el artículo 8 no hace público todo lo que el Estado tenga o posea, sino solo los actos y resoluciones de los órganos del Estado, así como sus fundamentos y procedimientos que utilicen».

31. Tribunal Constitucional, rol 2907-15-INA, considerandos $25 .^{\circ}$ y $26 .^{\circ}$; Tribunal Constitucional, rol 3111-16-INA, considerandos $31 .^{\circ}$ y $32 .{ }^{\circ}$; Tribunal Constitucional, rol 5950-19-INA, considerandos $13 .{ }^{\circ}$ y $17 . .^{\circ}$

32. De acuerdo con los criterios indicados en los principios marco sobre los derechos humanos y el medio ambiente de John Knox: «Los motivos para denegar una solicitud deben establecerse claramente e interpretarse de manera restrictiva, teniendo en cuenta el interés público en favor de la divulgación. Además, los Estados deben orientar a la población sobre el modo de obtener información ambiental», Asamblea General: Informe del Relator Especial sobre la cuestión de las obligaciones de derechos humanos relacionadas con el disfrute de un medio ambiente sin riesgos, limpio, saludable y sostenible. Doc. N.U. $\mathrm{A} / \mathrm{HRC} / 37 / 59,24$ de enero de 2018. Anexo: Principios marco sobre los derechos humanos y el medio ambiente, Principio marco 7. 
Primeramente, el artículo 4 párrafo 4 consagra el principio de efectividad en materia de derechos de acceso ambiental (Prieur y Mekouar, 2019: 9-37). ${ }^{33}$ Esta es una regla consuetudinaria en el derecho internacional e informa todo el sistema del derecho internacional (De Visscher, 1958: 601-609). Pero, además, el Acuerdo reitera en diversas ocasiones que los principios y reglas allí establecidos se encuentran regidos por el principio pro homine. En efecto, con diversa nomenclatura, el artículo 3 (Principios) letra $\mathrm{k}$ ), menciona el principio pro persona. $\mathrm{Y}$, a su turno, el artículo 4 párrafo 7 , consagra el principio pro homine o de favorabilidad de los derechos de acceso ambiental. Cabe reiterar que este es un principio clásico y transversal a los derechos humanos y encuentra su reconocimiento, inter alia, en el artículo 29 letra b) de la Convención Americana sobre Derechos Humanos. Incluso más, el artículo 4 párrafo 8 del Acuerdo consagra el principio de interpretación más favorable, como sigue: «En la implementación del presente Acuerdo, cada Parte avanzará en la adopción de la interpretación más favorable al pleno goce y respeto de los derechos de acceso».

Este principio de interpretación se conecta perfectamente con el gran principio regulado en el artículo 3 letra h), esto es, el principio de máxima publicidad, relacionado con el derecho de acceso a la información (Costa Cordella y Burdiles Perucci, 2019).

Por último, en esta materia el tratado establece que cuando se aplique la prueba del interés público, la autoridad o intérprete deberá ponderar el interés de no divulgar contra el beneficio público que se obtendría de divulgar la información, sobre la base de elementos de idoneidad, necesidad y proporcionalidad (artículo 5 párrafo 9). En definitiva, sería una aplicación concreta al acceso a la información ambiental del juicio de ponderación (UNEP, 2019: 98; Costa Cordella y Burdiles Perucci, 2019).

\section{La información entregada al Estado por empresas o corporaciones privadas no es necesariamente pública}

El Tribunal Constitucional interpreta que el alcance del artículo 8 de la Constitución comprendería solo actos, resoluciones, procedimientos y fundamentos de los órganos del Estado, dejando fuera de su ámbito de aplicación a las empresas privadas. Así, existe una restricción para acceder a la información que las empresas privadas, sujetas a fiscalización ambiental, entregan a las entidades que las controlan. ${ }^{34}$ En consecuencia, los informes y antecedentes que obren en poder del Estado, que fueron entregados por empresas privadas, se verían excluidos del marco constitucional del artículo 8 .

El Tribunal Constitucional concluye que el artículo 31 bis de la Ley 19.300, refe-

33. Sobre la efectividad en derecho al medio ambiente.

34. Tribunal Constitucional, rol 5950-19-INA, considerando decimocuarto. 
rente al acceso a la información ambiental, amplía el objeto de acceso al consagrar el acceso a la información que se encuentre en poder de la Administración, contraviniendo lo consagrado en la Constitución, ya que el constituyente, si hubiera querido hacer pública toda la información en poder o producida por la Administración, no habría realizado la enumeración taxativa respecto de actos, resoluciones, procedimientos y fundamentos. Añade que, respecto de la información entregada al Estado por empresas privadas, no sería susceptible de ser accedida por la vía del ejercicio del derecho al acceso a la información ambiental, ya que, en la reforma constitucional del año 2005 esto quedó expresamente descartado. ${ }^{35}$

Si bien se reconoce el carácter especial del acceso a la información ambiental, se señala que este debe ejercerse conforme a la Constitución y agrega que para ejercer este derecho:

- es necesario, en primer lugar, que se solicite cierta información; esta puede ser, como la propia norma se encarga de señalar, «escrita, visual, sonora, electrónica o registrada de cualquier otra forma»;

- en segundo lugar, esa información debe cumplir con dos requisitos; por una parte, debe estar en poder de la Administración, y, por la otra, debe referirse a «información de carácter ambiental», que es toda aquella que verse sobre el medio ambiente o sobre sus elementos;

- en tercer lugar, es necesario que se siga el procedimiento establecido en la Ley de Transparencia para solicitarla. ${ }^{36}$

El Tribunal Constitucional agrega, como elemento adicional, que la contravención constitucional está dada por lo siguiente:

Porque no se vincula a actos o fundamentos (salvo la letra c) y e) del artículo 31 bis). Como ya se ha indicado en esta sentencia, el constituyente no quiso que toda la información fuera pública. Por eso es muy cuidadoso en señalar cuál lo es.

En segundo lugar, porque exige que la información esté en poder de la Administración, independientemente de si ésta la produjo, o si es información privada aportada por empresas.

En tercer lugar, la información que se solicita es información de empresas específicas. Ello también excede la evolución de nuestra regulación y el propio artículo 8o, que se refiere a actos y resoluciones de órganos del Estado. ${ }^{37}$

35. Tribunal Constitucional, rol 2907-15-INA, considerando $38 .^{\circ}$ y $40 .^{\circ}$; rol 5950-19-INA, considerando $14 .^{\circ}$

36. Tribunal Constitucional, rol 2907-15-INA, considerando 46..$^{\circ}$, rol 4986-2018-INA, considerandos $30 .^{\circ}$ a $32 .^{\circ}$; rol 5950-19-INA, considerandos $31 .^{\circ}$ y $32 .^{\circ}$

37. Tribunal Constitucional, rol 2907-15-INA, considerando $47^{\circ}$; rol 4986-2018-INA, considerando $33 .^{\circ}$; rol 5950-19-INA, considerando $33 .^{\circ}$ 
Cabe señalar que los votos en contra postularon el rechazo del requerimiento basados, primero, en entender que el artículo 8 de la Constitución consagra el principio de publicidad y, como tal, su aplicación tiene que tener el máximo alcance posible y sienta las bases mínimas que desarrollará el legislador. Por ello, las normas legales desarrollaron el contenido constitucional de este principio y pueden ampliar la extensión de la publicidad sin ques esta ampliación sea una contravención material a la carta fundamental. Este razonamiento satisface los estándares consagrados en el Acuerdo de Escazú relativos al principio pro homine y pro natura (artículo 1 y $3, \mathrm{k}$ ).

En cuanto a la información ambiental y su régimen especial de publicidad, este está sustentado por la Ley 19.300, que introduce el concepto de información ambiental, el que comprende toda la información en poder de la Administración, en diversos formatos referente a los elementos y componentes del medio ambiente. Esto caracteriza este derecho en razón de la incidencia de la información ambiental como herramienta de control en la toma de decisiones públicas que puedan afectar el medio ambiente, la vida y salud de las personas, pero también es imprescindible para la protección del medio ambiente y la prevención de problemas ambientales..$^{38}$

Es deber del Estado garantizar el acceso a la información ambiental respecto de las actividades que podrían afectar el medio ambiente ya que se trata de asuntos de interés público. En razón de la protección del medio ambiente, el Estado debe proporcionar a toda persona, sin necesidad de tener un interés legítimo, mecanismos y procedimientos de solicitud de información, pero, además, debe recopilar y difundir de forma proactiva información ambiental..$^{39}$

Finalmente, la línea jurisprudencial restrictiva del Tribunal Constitucional no alcanza a satisfacer el estándar de acceso a la información ambiental del Acuerdo de Escazú. Dicho de otro modo, excluir del acceso a la información ambiental a las informaciones proporcionadas por las personas privadas que se encuentren en poder de la Administración implica desconocer que en materia de medio ambiente hay un parámetro diferente, más exigente, que rige, con principios y características propias (Bertazzo, 2019: 15 y 16). En este sentido, el artículo 2 letra c) del Acuerdo de Escazú señala:

38. Voto en contra ministros Gonzalo García Pino y Domingo Hernández Emparanza, rol 2907-15INA, considerandos 9. ${ }^{\circ}$ a $11 .^{\circ}$. En el mismo sentido, voto en contra de los ministros Gonzalo García Pino y Nelson Pozo Silva, rol 3111-16- INA, considerandos 9. ${ }^{\circ}$ a $11 .^{\circ}$ y 13 . Véase también voto en contra de los ministros Gonzalo García Pino, Domingo Hernández Emparanza, Nelson Pozo Silva y María Pía Silva Gallinato, rol 5950-19-INA, considerandos $8 .^{\circ}$ a $14 .{ }^{\circ}$ Voto en contra de los ministros Domingo Hernández Emparanza, Nelson Pozo Silva y María Pía Silva Gallinato, rol 4886-18-INA, considerandos 9. a $13 . .^{\circ}$

39. Corte IDH, Opinión Consultiva OC 23/17, del 15 de noviembre de 2017, párr. 225. Véase también el voto en contra de los ministros Gonzalo García Pino, Domingo Hernández Emparanza, Nelson Pozo Silva y María Pía Silva Gallinato, rol 5950-19-INA, considerando decimocuarto. 
Por información ambiental se entiende cualquier información escrita, visual, sonora, electrónica o registrada en cualquier otro formato, relativa al medio ambiente y sus elementos y a los recursos naturales, incluyendo aquella que esté relacionada con los riesgos ambientales y los posibles impactos adversos asociados que afecten o puedan afectar el medio ambiente y la salud, así como la relacionada con la protección y la gestión ambientales (Costa y Burdiles, 2019: 189-211).

Como se puede apreciar, la interpretación restrictiva del Tribunal Constitucional es contraria a los estándares establecidos en el derecho internacional del medio ambiente y el derecho internacional de los derechos humanos, y que han sido recogidos en el Acuerdo de Escazú.

\section{Jurisprudencia ordinaria}

En un recurso presentado por un reclamo acogido parcialmente por el CPLT, el Tribunal de Alzada se pronunció sobre una colisión entre publicidad y derechos comerciales y/o económicos de particulares, en materia de acceso a la información ambiental. En este caso, se pueden desprender algunos criterios en materia de acceso a la información ambiental.

\section{Amplio acceso a la información ambiental para permitir el control social}

En este sentido, la Corte de Apelaciones de Santiago estimó que:

Desde luego, en el contexto de un Estado democrático de derecho, es necesaria la existencia de una fiscalización o control social, que debe ejercerse por los ciudadanos, sin perjuicio del control que le cabe al propio Sernapesca, respecto de las empresas del rubro del cultivo de la especie salmón, para así por un lado, poder fiscalizar el debido cumplimiento de las funciones públicas por parte de los órganos del Estado, que como precisa la Constitución Política, se deben al principio servicial sobre la persona humana y cuya finalidad esencial es promover el bien común. Asimismo, permite el escrutinio público sobre las propias empresas o entidades fiscalizadas por el respectivo órgano de la Administración, que permita entonces apreciar el modo como se respeta la legislación que enmarca su actuación económica, en el terreno del ejercicio de la libertad de ejercer una actividad económica lícita, pero por cierto apegada a la Constitución y a las leyes. ${ }^{40}$

40. Corte de Apelaciones de Santiago, rol 11771-2015, sentencia de 31 de mayo de 2016, considerando $32 .^{\circ}$ 


\section{La publicidad y la transparencia es la regla general y el hermetismo, la excepción}

Ahora bien, el análisis de la Corte de Apelaciones parte de la premisa de que la publicidad y la transparencia es la regla general y el hermetismo, la excepción. Además, entiende que existe una presunción simplemente legal de publicidad respecto de la información que está en poder del Estado y que requiere ser desvirtuada para que se aplique la reserva. Por otra parte, sostiene que respecto de la información solicitada sobre cantidades y clases de antibióticos usados por la industria del salmón de cultivo durante el año 2014, hay un interés público comprometido, que es la salud de las personas y la protección del medio ambiente, indicando que ante la colisión entre el principio de publicidad y la afectación de intereses económicos o comerciales, se debe resolver dicho conflicto bajo las premisas de una sociedad democrática que permita el control social. ${ }^{41}$

\section{No habría acceso a la información ambiental cuando se encuentra comprometido un derecho económico o comercial}

Un argumento que aparece en las prevenciones o disidencias es que no hay acceso a la información ambiental cuando se encuentra comprometido un derecho económico o comercial. En efecto, el voto disidente prioriza el hermetismo por sobre la publicidad y transparencia, es decir, en la balanza gana la excepción por sobre la regla general. Resulta llamativa esta conclusión en la medida en que no se acredita, por parte de la empresa afectada, cómo y en qué medida afectaría sus derechos económicos o comerciales el acceso a la información disociada sobre la utilización de antimicrobianos segregado por tipo de antibiótico, ya que no desvirtúa la presunción de pública de la misma. Por otra parte, esto se trata de información de interés público que tiene incidencia en toda la comunidad y en que la ponderación de conflicto de derechos debería prevalecer el acceso a la información de relevancia ambiental por sobre la reserva.

En causa rol 34.432-2016 ante la Corte Suprema, conociendo de un recurso de queja deducido por un conjunto de empresas salmoneras en contra de la sentencia rol 11771-2015 de la Corte de Apelaciones de Santiago, en el voto disidente que estuvo por acogerlo, señaló que la información disociada sobre la utilización de antimicrobianos segregado por tipo de antibiótico cae dentro de la causal de reserva que puede afectar derechos económicos o comerciales, ya que se debería entender que dicha información es confidencial y estratégica de cada compañía y que le proporcionan

41. Corte de Apelaciones de Santiago, rol 11771-2015, sentencia de 31 de mayo de 2016, considerandos $35 .^{\circ}$ y $37^{\circ}$

Conte de Apelaciones de Santiago, rol 11771-2015, sentencia de 31 de mayo de 2016, considerandos $35 .^{\circ}$ y $37^{\circ}$ 
como tal una ventaja competitiva respecto de sus competidores. ${ }^{42}$ Llama la atención que los disidentes entienden que el acceso a la información es un derecho fundamental autónomo, pero además, que es una facultad que permite el ejercicio y defensa de otros derechos fundamentales. Partiendo de esta premisa, la argumentación del fallo en comento se centra en la interpretación y aplicación de las excepciones a la publicidad y transparencia de la actividad estatal y la que obre en su poder, como lo sería el caso de las empresas salmoneras. Ahora bien, el voto disidente no pondera el interés público de la información dado el impacto que puede tener sobre el medio ambiente y la salud de las personas ni, a su vez, se pronuncia sobre el deber constitucional y convencional de protección y preservación de medio ambiente.

Aquí se aprecia el contraste con la interpretación del principio de máxima divulgación, transparencia y buena fe que son rectores en materia de acceso a la información ambiental. Entender que la reserva de información sobre antibióticos utilizados por empresas salmoneras debería primar por sobre la publicidad por afectar derechos de particulares, es perder de vista el interés público de la información ambiental y el rol que juega como mecanismo de control social de las autoridades, y para la protección del medio ambiente y la salud de la población, ambos derechos fundamentales reconocidos en la Constitución.

\section{El interesado en un procedimiento administrativo puede recurrir al Tribunal Ambiental o al CPLT, según mejor sirva a sus derechos}

En el caso rol 41.790-2016, ante el máximo tribunal, los hechos consistían en que la Superintendencia del Medio Ambiente rechazó el acceso a obtener una copia del expediente administrativo de una fiscalización, basado en una causal de reserva del artículo 21 número 1 letra $b$ (referente a antecedentes o deliberaciones previas a la adopción de una resolución, medida o política). ${ }^{43}$ El Tribunal Ambiental declaró su incompetencia en virtud de lo dispuesto en el artículo 31 bis y 31 quáter de la Ley 19.300, ya que los solicitantes deberían haberse dirigido al CPLT, que es el procedimiento establecido para el acceso a la información ambiental, regulado en la Ley 20.285.

En este caso, la Corte Suprema sostuvo que el interesado en un procedimiento administrativo, a quien se le deniega acceso al procedimiento de fiscalización que lleva la Superintendencia del Medio Ambiente, puede recurrir al Tribunal Ambiental o al CPLT, según mejor proteja sus derechos. La Corte considera que ante dos normas

42. Corte Suprema, rol 34.432-2016, voto disidente del ministro Carlos Aránguiz y del abogado integrante Arturo Prado, sentencia del 6 de julio de 2017.

43. Corte Suprema, rol 41.790-2016, sentencia de 7 de agosto de 2017, C. $8^{\circ}$. «Si la Ley 20.285 no es especial en relación a la Ley 20.600, no es posible justificar su aplicación preferente y excluyente. En estas condiciones, las recurrentes han podido reclamar de la negativa a entregar las copias solicitadas ante la justicia ambiental, en virtud de lo dispuesto en el artículo 17 núm. 3 de la Ley 20.6oo». 
de carácter especial, no puede aplicarse de forma preferente y excluyente una sobre otra. Más bien surge un derecho de opción del interesado para decidir si recurre a la jurisdicción ambiental o al CPLT. Así, la Corte entiende que la jurisdicción especial ambiental sería competente para conocer de un reclamo ante la negativa de acceso a información ambiental. Asimismo, en materia de aplicación de causales de reserva, indica que la Administración debe fundar debidamente la decisión de reserva, obedeciendo a un criterio de necesidad y temporalidad.

En palabras de Pilar Moraga, esto abre la puerta a que los tribunales especializados conozcan de la impugnación de la negativa al acceso a la información ambiental. A su vez, la Corte entiende que el acto que deniega el acceso a la información deja en un estado de indefensión al administrado, por lo que la motivación de la reserva debe ser más intensa para mantenerse en el tiempo, es decir, debe existir una justificación, pero esta deberá actualizarse para mantenerse en el tiempo. ${ }^{44}$

\section{Deber de gestionar, generar y recopilar la información, sea de fuentes públicas o privadas}

En el caso rol 5888-2019, ante la Corte Suprema, relativo al acceso a la información ambiental en el contexto de la contaminación de Quintero, Ventanas y Puchuncaví, se reprochó el incumplimiento del deber de información del Estado en lo que respecta al registro de contaminantes, ya que este no solo tiene la obligación de administrar la información, sino también de generar y recopilar la información técnica y científica. ${ }^{45}$ La Corte utilizó una interpretación extensiva de dicha obligación, ya que el deber de informar no se limita a la información disponible, por el contrario, el Estado debe generar la información necesaria para evitar situaciones como las que motivaron el caso. Si la información proviene de fuentes privadas, el Estado debe velar igualmente por el cumplimiento de esta obligación como medida efectiva para lograr la adecuada fiscalización y prevención de situaciones de contaminación ambiental. ${ }^{46}$ Otro elemento relevante es que la Corte aplicó en su decisión diversos tratados internacionales y la Declaración de Río.

En resumen, según se puede observar, la jurisprudencia de la Corte Suprema está en una línea más afín a la naturaleza del derecho al acceso a la información ambiental, aplicando una interpretación expansiva del derecho, considerando el carácter eminentemente público de la información concerniente a materias ambientales.

44. Pilar Moraga, «Sentencia rol 41.790-2016 de la Corte Suprema, de 7 de agosto de 2017», Centro de Derecho Ambiental Universidad de Chile, disponible en https://bit.ly/3FpiwEj.

45. Corte Suprema, rol 5888-2019, sentencia del 28 de mayo de 2019.

46. Pilar Moraga, «Sentencia Tribunal Ambiental de Santiago: Contaminación del aire, acceso a la información y prevención», Actualidad Jurídica Ambiental, disponible en https://bit.ly/3EmATyo. Corte Suprema, causa rol 5888-2019, sentencia del 28 de mayo de 2019, considerandos $11 .^{\circ}, 12 .^{\circ}, 16 .^{\circ}$ y $22 .^{\circ}$. 


\section{Conclusiones}

Si bien la Ley 19.300 acuña un concepto general de derecho al acceso a la información ambiental, no establece un mecanismo especial para concretarlo. En este sentido, remite la tutela de este derecho al órgano general encargado de velar por el acceso a la información, que es el CPLT. Este órgano no está especializado en materia ambiental. En este sentido, adquiere relevancia la necesidad de disponer de un procedimiento especial de acceso a la información ambiental encargado a un órgano especializado.

Los tribunales aplican el medio consagrado en la Ley 20.285 como mecanismo general de justiciabilidad del derecho al acceso a la información ambiental, utilizando los criterios generales de reserva, sin considerar los criterios o estándares específicos del acceso a la información ambiental. El acceso a la información pública no es lo mismo que el acceso a la información ambiental, ya que esta tiene estándares más exigentes debido a la especial intensidad del interés público involucrado. Un ejemplo consiste en que al ámbito de las restricciones en materia ambiental se le aplica el principio de máxima publicidad, que conlleva la existencia de circunstancia excepcionalísimas de reserva. Además, no basta alegar la causal para restringir el acceso a la información; es necesario que la parte que la alega acredite fehacientemente la concurrencia de los requisitos para que proceda.

Por otra parte, llama la atención que en la concreción de este derecho encontramos diversos obstáculos para su ejercicio, partiendo por la interpretación restrictiva que ha hecho el Tribunal Constitucional, que ha entendido que el ámbito protegido para el acceso a la información ambiental por el artículo 31 bis de la Ley 19.300 excede el contenido cubierto por la norma constitucional. Por otra parte, desconoce el régimen especial de la información ambiental. Así, se ha observado que las excepciones a la publicidad, es decir, las causales de secreto, en especial las referentes de los derechos económicos o comerciales de privados tiene una prevalencia por sobre el acceso de la información ambiental. En otras palabras, se priorizan los derechos de particulares por sobre el derecho social colectivo de protección del medio ambiente, en que incide el acceso a la información ambiental. Esta interpretación de los jueces constitucionales en Chile no se encontraría en conformidad con el derecho internacional de los derechos humanos, ya que una interpretación restrictiva del acceso a la información ambiental es contraria a los estándares de derechos humanos, en especial, a los principios de progresividad e interpretación pro natura y expansiva, claramente recogidos en el Acuerdo de Escazú.

Finalmente, podemos agregar que en el contexto del proceso constituyente chileno podría concretarse este derecho expresamente consagrando, además de un mecanismo de tutela que responda a sus particularidades. Es de especial importancia indicar que el Acuerdo de Escazú debería ser considerado como un insumo valioso para la discusión constitucional, aunque este no tenga el carácter de vinculante para Chile. 


\section{Referencias}

Astudillo Muñoz, Jorge (2019). «Algunas ideas sobre necesidad de dar reconocimiento constitucional al derecho de acceso a la información pública». En Gonzalo Aguilar (coord.), Nuevos derechos para una nueva constitución (pp. 159-173). Valencia: Tirant lo Blanch.

Beltrao, Jane, José Claudio Monteiro, Itziar Gómez y otros (2014). Derechos humanos de los grupos vulnerables. Barcelona: Universidad Pompeu Fabra.

Bermúdez Soto, Jorge (2010). «El acceso a la información pública y la justicia ambiental». Revista de Derecho (Pontificia Universidad Católica de Valparaíso), 34: 571-596.

Bertazzo, Silvia (2019). «El acceso a la información ambiental en chile». Veredas do Direito, 16 (34): 11- 39.

Camacho Cepeda, Gladys (2013). «La Contraloría General de la República y transparencia». Revista de Derecho Público, 78: 27-50.

-. (2018). «Sobre la transparencia, el derecho de acceso a la información pública y los deberes de publicidad. Su diferencia conceptual y práctica». Revista de Derecho Público, número especial: 75-95.

CePAl (2018). «Acceso a la información, la participación y la justicia en asuntos ambientales en América Latina y el Caribe. Hacia el logro de la Agenda 2030 para el Desarrollo Sostenible». Disponible en https://bit.ly/3EiBoLv.

Consejo para la Transparencia (2020). «Experiencia comparada sobre la consagración constitucional del derecho de acceso a la información y la protección de datos personales». Disponible en https://bit.ly/32uwgJP.

Cordero, Luis y Valentina Durán (2017). Derribando mitos: Propuestas para mejorar el acceso a la justicia ambiental en Chile. Informe de Políticas Públicas 13. Santiago: Espacio Público.

Costa Cordella, Ezio y Gabriela Burdiles Perucci (2019). «El derecho humano al medioambiente: Nuevos avances en su comprensión en América Latina y el Caribe». Anuario de Derechos Humanos, 15 (2): 189-211.

De VIssCher, Charles (1958). «Observations sur l'effectivité en droit international public». Revue Général de Droit International Public, 62: 601-609.

Droguett González, Carmen (2019). «El derecho de acceso a la información pública como derecho fundamental y su reconocimiento en la jurisprudencia constitucional chilena. Avances y desafíos para una mayor transparencia a 10 años de la Ley 20.185». Revista Española de la Transparencia, 9: 133-159.

Fernández González, Miguel Ángel (2009). «Objeto del principio de publicidad, a propósito del artículo 5 de la Ley 20.285». Revista de Derecho Público, 71: 47-63. 
Fuentes, Carlos y María de las Nieves Cenicacelaya (2019). «El acceso a la información pública como derecho humano instrumental para la tutela del ambiente». Revista Anales (Universidad Nacional de La Plata), 16 (49): 171-194.

García, Gonzalo y Pablo Contreras (2009). «Derecho de acceso a la información en Chile: Nueva regulación e implicancias para el sector de la defensa nacional». Estudios Constitucionales, 7 (1): 137-175.

Isensee Rimassa, Carlos y Jorge Muñoz Severino (2013). «Acceso a la información pública y principio de transparencia concepto, bloque de constitucionalidad y test de proporcionalidad». Derecho y Justicia, 3: 45-72.

Nogueira Alcalá, Humberto (2015). «El bloque constitucional de derechos en Chile, el parámetro de control y consideraciones comparativas con Colombia y México: doctrina y jurisprudencia». Estudios Constitucionales, 13 (2):301-350.

Olivares Gallardo, Alberto (2018). "Contenido y desarrollo del principio pro natura. Hacia la protección integral del medio ambiente». Ius et Praxis, 24 (3): 619-650.

PrIeUR, Michel y Mohamed Ali Mekouar (2019). «Measuring the effectivity of environmental law through legal indicators in the context of francophone Africa». Revista de Direitos Difusos, 71 (81): 9-37.

Ramírez Parada, Felipe (2011). «Acceso a la información ambiental». Revista Chilena de Derecho, 38 (2): 311-339.

SANZ SAlguero, Francisco Javier (2017). "Grado de equivalencia entre la protección de los datos personales y el derecho de acceso a la información pública». Revista de Derecho de la Pontificia Universidad Católica de Valparaíso, XLVIII: 135-163.

Sedano Lorenzo, Jesús (2019). «El principio de acceso a la información ambiental». En Yann Aguila, Carlos de Miguel Perales, Víctor Tafur y Teresa Parejo (eds.). Principios de derecho ambiental y Agenda 2030 (pp. 182-196). Valencia: Tirant lo Blanch.

Tello, Cristóbal, Marcelo Cerna y Andrés Pavón (2009). «Acceso a la información pública: Los desafíos del Consejo de la Transparencia». Anuario de Derechos Humanos, 5: 193-204.

UNEP (2019). Environmental Rule of Law, First Global Report. Nairobi: UNEP, 2019.

VIAL, Tomás (2007). «La ley de transparencia y acceso a la información pública: esquema general y regulación del derecho de acceso a la información». Anuario de Derecho Público 2007: 114-143.

Viera-Gallo Quesney, José Antonio (2013). «El Tribunal Constitucional y el derecho de acceso a la información pública». Revista de Derecho (Universidad Finis Terrae), 1 (1): 173-209. 


\section{Agradecimientos}

El autor agradece el apoyo en la investigación realizada por María Ignacia Sandoval. Este trabajo se enmarca en el Proyecto Fondecyt Regular 1190423 titulado «Análisis de los estándares internacionales sobre el derecho de acceso a la información, a la participación y a la justicia ambiental y su concreción en el derecho interno», del que el autor es investigador principal.

\section{Sobre el autor}

Gonzalo Aguilar es profesor de Derecho Constitucional, Internacional, Ambiental y Derechos Humanos del Centro de Estudios Constitucionales de la Universidad de Talca. Director del Magister en Derecho Constitucional del mismo centro. Abogado, doctor en Derecho (España), magíster en Relaciones Internacionales (España), master en Derechos Humanos y Derecho Humanitario (Francia), y posdoctorado en el Max Planck Institute for Comparative Public Law and International Law (Heidelberg, Alemania). Su correo electrónico es gaguilar@utalca.cl. (D) https://orcid. org/0000-0001-9728-6727. 
La Revista de Derecho Ambiental, del Centro de Derecho Ambiental de la Facultad de Derecho de la Universidad de Chile, es un espacio de exposición y análisis en el plano académico del derecho ambiental. Su contenido se presenta a través de doctrina, jurisprudencia y recensiones, y aborda diversas materias relacionadas con la gestión, institucionalidad y herramientas de protección ambiental y desarrollo sustentable. Se presentan artículos de diferentes autores y autoras en los que se analizan y abordan casos y temas jurídico-ambientales de creciente interés y actualidad.

\author{
DIRECTORA \\ Valentina Durán Medina \\ EDITORES \\ Jorge Ossandón Rosales \\ y Antonio Pulgar Martínez \\ SITIO WEB \\ revistaderechoambiental.uchile.cl \\ CORREO ELECTRÓNICO \\ revistada@derecho.uchile.cl \\ LICENCIA DE ESTE ARTÍ́CULO \\ Creative Commons Atribución Compartir Igual 4.o Internacional
}

La edición de textos, el diseño editorial

y la conversión a formatos electrónicos de este artículo

estuvieron a cargo de Tipográfica

(www.tipografica.io) 